\title{
A study on tuberculosis treatment outcome in known diabetic patients treated under Revised National Tuberculosis Control Program in Bengaluru
}

T. S. Ranganath, B. M. Shivaraj

Department of Community Medicine, Bangalore Medical College and Research Institute,

Bengaluru, Karnataka, India

Address for the Correspondence:

Dr. T. S. Ranganath, Department of Community Medicine, Bangalore Medical College and Research Institute, Bengaluru - 560 002, Karnataka, India. E-mail: tsranga1969@gmail.com

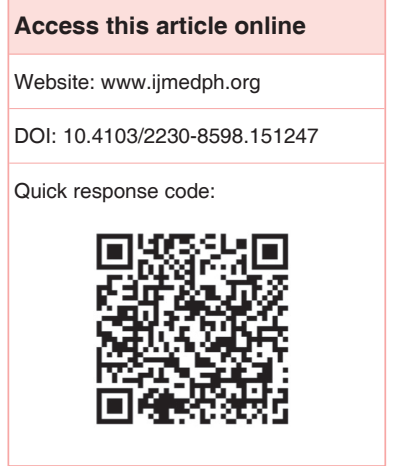

Background: The rising prevalence of diabetes mellitus (DM) in high tuberculosis (TB) burden countries may adversely affect TB control. Revised National Tuberculosis Control Program (RNTCP) prescribes the same TB treatment regimen that is used for non-diabetics to the diabetics. Under the program setting, there is a need for study on successful treatment outcome of TB patients with known DM. Objective: The aim was to analyze the TB treatment outcome in patients with known DM treated under RNTCP setting in an urban area. Materials and Methods: After cluster sampling among the 9 TB Units in Bengaluru 5 were selected randomly. 75 TB-DM patients and 150 TB without Diabetes were enrolled into the study and followed-up for their treatment outcome. Results: Of the 75 TB-DM patients $72 \%$ were males, and $28 \%$ were females. $>90 \%$ of the patients were of age above 40 years old. Overall treatment outcome was $81 \%$ and $87 \%$ among TB-DM and TB without DM, respectively. It was not statistically significant (Fisher's exact test $P=0.3256$ ). Conclusion: RNTCP's directly observed treatment strategy (DOTS) regimen holds good for TB patients with and without DM. The DM co-morbidity did not significantly change the TB treatment outcome. Hence, the current DOTS regime under RNTCP can be applied to the TB-DM co-morbid patients.

Key words: Diabetes mellitus, directly observed treatment strategy, tuberculosis, tuberculosis-diabetes mellitus, Revised National Tuberculosis Control Program

\section{INTRODUCTION}

India, a developing country, has the highest tuberculosis (TB) burden in the world, with an estimated 2.3 million cases annually. ${ }^{[1]}$ TB is seen more commonly in immune suppressed individuals. The rising prevalence of diabetes mellitus (DM) in high TB burden countries may adversely affect TB control. ${ }^{[2]}$ In 2012, there were an estimated 63 million prevalent cases of DM in India. ${ }^{[3]}$ There is now good evidence that people with DM have 2-3 times the risk of developing active TB compared with those who do not have DM. ${ }^{[4]}$ Patients with dual disease appear to have an increased frequency of adverse TB treatment outcomes. ${ }^{[5]}$ Revised National Tuberculosis Control Program (RNTCP) prescribes the same TB treatment regimen that is used for non-diabetics to the diabetics.

A study in National Institute for Research in Tuberculosis, Chennai has evaluated the effectiveness of category-I regimen (recommended for all the new smear-positive patients in the Indian TB program) for the treatment of sputum positive pulmonary TB among DM patients and has found it to be as effective as it is for non-diabetics, but this was done in the absence of an appropriate comparison group. A stronger evidence base is hence required to clarify whether TB (any type) treatment outcome among diabetics is any different from that among non-diabetics with the current RNTCP guidelines. ${ }^{[6]}$

This study focuses on such need where we can create more evidence base for the TB-DM co-morbidity management under the RNTCP setting. Hence, the study was done with the following objective: To analyze the TB treatment outcome in patients with known DM treated under RNTCP setting in an urban area. 


\section{MATERIALS AND METHODS}

A prospective study was carried out on TB and co-morbid DM patients registered under RNTCP in 5 TB units (TU) in Bruhat Bengaluru Mahanagara Palike (BBMP), Bengaluru. In Karnataka, as on 2009 the average treatment success outcome among newly notified cases of all kinds of Tuberculosis (smear +ve, smear -ve and extra pulmonary) was $84 \% .^{[7]}$

If in reality the Tuberculosis treatment success rate is $10 \%$ lesser than the general population, then to detect this difference in treatment success outcome among TB-DM, our minimum sample size of TB-DM patients would be around 63 TB-DM co-morbid patients. However, we were able to study a sample of 75 TB-DM and 150 matched controls with TB disease.

Cluster sampling for selecting the cases: RNTCP has divided the BBMP area into 9 TU's, the same was used as clusters in this study. Since each TU was expected to have around 15 TB-DM patients per year, 5 TU's would provide sufficient subjects for this study. So total of 75 TB-DM patients were chosen and double the number of TB patients without DM was chosen from the same TU's by convenient sampling and followed-up as a matched control. Two controls for each case. The study was done during the period of November 2011 to May 2013.

All patients diagnosed (as per the case definitions of the RNTCP II) with Tuberculosis, registered (from November 2011 onwards) and put on directly observed treatment strategy (DOTS) under the TUs, and those among them who are also already diagnosed to be having diabetes were chose as cases. Controls were chosen after age/gender/socio economic states (SES) matching. All those who did not wish to participate, age $<18$ years, pregnant, lactating mothers and TB patients with HIV co-infection were excluded from the study.

Data collection was started after obtaining clearance from institutional ethical committee. Among the selected TU patients were enrolled after obtaining informed consent from the patient. Each patient was interviewed at their respective DOTS centers by the investigator with the help of RNTCP - DOTS health workers. Subjects were interviewed 3 times during the entire DOTS with a pre-tested and semi-structured questionnaire. Interviews were held as follows:

1. First one at the beginning of intensive phase for collection of demographic data and noting the type of TB and DOTS category.

2. Second one at the end of continuation phase and

3. Third one at the end of the continuation phase.

Data were entered onto computer excel sheet; subsequently it was analyzed using Descriptive statistics (means, proportions, percentages), and Fisher's exact test.

Outcomes were measured according to standard definitions.

Successful treatment: "Cured" and "treatment completed" were considered as:
Successful TB treatment. Unsuccessful treatment: Death (irrespective of the cause) and treatment failure were considered as unsuccessful TB treatment. ${ }^{[8]}$

\section{RESULTS}

Of the 75 TB-DM patients $72 \%$ were males and $28 \%$ were females. $>90 \%$ of the patients were of age above 40 years old and the majority belonged to Hindu Religion in both the groups. The baseline characteristics, sputum smear status during treatment and treatment outcomes for TB patients with and without DM, are shown in Table 1.

There were no significant differences in sputum conversion amongst sputum positive pulmonary TB patients among TB-DM and TB without DM group. And also overall final treatment outcome in both the group did show any statistically significant changes. Overall

\begin{tabular}{|c|c|c|c|}
\hline Characteristic & $\begin{array}{l}\text { TB with DM } \\
(n=75) n(\%)\end{array}$ & $\begin{array}{l}\text { TB without DM } \\
(n=150) n(\%)\end{array}$ & Remarks \\
\hline \multicolumn{4}{|l|}{ Gender } \\
\hline Male & $54(72)$ & $106(71)$ & \\
\hline Female & $21(28)$ & $44(29)$ & \\
\hline \multicolumn{4}{|l|}{ Age, years } \\
\hline$>40$ & $69(92)$ & $137(91.33)$ & \\
\hline$<40$ & $06(08)$ & $13(8.66)$ & \\
\hline \multicolumn{4}{|l|}{ Religion } \\
\hline Hindu & $60(80)$ & $122(81.33)$ & \\
\hline Muslim & $09(12)$ & $15(10)$ & \\
\hline Christian & $06(08)$ & $13(8.66)$ & \\
\hline \multicolumn{4}{|l|}{ DOTS category } \\
\hline Category I & $60(80)$ & $122(81.33)$ & \\
\hline Category II & $15(20)$ & $28(18.66)$ & \\
\hline \multicolumn{4}{|l|}{$\begin{array}{l}\text { Disease } \\
\text { classification }\end{array}$} \\
\hline $\begin{array}{l}\text { Pulmonary } \\
\text { smear positive }\end{array}$ & $33(44)$ & $70(46.66)$ & \\
\hline $\begin{array}{l}\text { Pulmonary } \\
\text { smear negative }\end{array}$ & $15(20)$ & $30(20)$ & \\
\hline Extra pulmonary & $27(36)$ & $50(33.33)$ & \\
\hline $\begin{array}{l}\text { Sputum smear } \\
\text { conversion }\end{array}$ & $(n=33)$ & $(n=70)$ & \\
\hline \multicolumn{4}{|l|}{$\begin{array}{l}\text { End of intensive } \\
\text { phase }\end{array}$} \\
\hline Converted & $25(75.75)$ & $58(82.85)$ & \multirow{3}{*}{$\begin{array}{c}P=0.2389 \\
\text { (Fisher's } \\
\text { exact test) }\end{array}$} \\
\hline Not converted & $07(21.21)$ & $08(11.42)$ & \\
\hline Unknown & $01(03.03)$ & $04(5.71)$ & \\
\hline \multicolumn{4}{|l|}{ End of treatment } \\
\hline Converted & $26(78.78)$ & $60(85.71)$ & \multirow{3}{*}{$\begin{array}{c}P=0.5381 \\
\text { (Fisher's } \\
\text { exact test) }\end{array}$} \\
\hline Not converted & $05(15.15)$ & $07(10)$ & \\
\hline Unknown & $02(06.06)$ & $03(4.29)$ & \\
\hline \multicolumn{4}{|l|}{$\begin{array}{l}\text { Overall final } \\
\text { treatment outcome }\end{array}$} \\
\hline $\begin{array}{l}\text { Treatment } \\
\text { success }\end{array}$ & $61(81)$ & $130(87)$ & $\begin{array}{c}P=0.3256 \\
\text { (Fisher's }\end{array}$ \\
\hline Other outcomes & $14(19)$ & $20(13)$ & exact test) \\
\hline
\end{tabular}

$\mathrm{DM}=$ Diabetes mellitus, $\mathrm{TB}=$ Tuberculosis, DOTS = directly observed treatment strategy 
success rate of the DOTS is $81.32 \%$ in TB-DM group, and other outcomes are $18.68 \%$. This is almost same with the $82 \%$ success rate of treatment in the report given by central TB division where it showed $82 \%$ treatment success in Bengaluru city. Overall success rate of the DOTS is $86.66 \%$ in TB patients without DM group, and other outcomes are $13.33 \%$. This finding is higher than the $82 \%$ success rate of treatment in the report given by central TB division where it showed $82 \%$ treatment success in Bengaluru city. ${ }^{[7]}$ A comparison of treatment outcomes in both the groups shows that there is no significant difference (Fisher's exact test $P=-0.3256$ ) between the outcomes in TB-DM and TB without DM patients.

\section{DISCUSSION}

In this prospective study on treatment outcome of TB-DM and TB without DM, we found no significant difference in the outcome of the treatment. It was observed that TB-DM and TB without DM patients comprised mainly of males in their economically productive age group coming from the middle and lower socio-economic status. Majority of the TB-DM co-morbid patients were belonged to lower middle class. The study population mainly comprised pulmonary TB patients. Majority of them received Category I of DOTS regimen.

Since we wanted to check the outcome of TB disease under Program setting, we did not modify any RNTCP guidelines. All the patients were followed up as like a routine DOTS regimen, and the progress was noted. Of the 75 TB-DM patients, $81 \%$ were successfully treated, and $19 \%$ had other outcomes. Among the patients of TB without DM the treatment success was $87 \%$. This difference in treatment outcome in two groups was not statistically significant. The sputum conversion rates were also not statistically significant among the two comparison groups. There were no any other factors such as substance abuse, other morbidities during treatment course, assessed to check their influence in treatment outcome of the patients.

However, we cannot overlook the integrated management of the patient's illness. Among patients with DM and active TB, all aspects of treatment, case management, monitoring of side effects and complications, patient support and health education for both TB and DM should be optimized, as per national guidelines and/or best practice adapted to available resources. Appropriate cross-referral of
TB and DM cases should be ensured while integrated approaches for diagnosis, management and prevention should be explored.

The strength of the study was that it was conducted in a program setting with no additional resources. Some of the limitations were; DM patients were not screened with invasive blood investigations before including them into the study.

\section{CONCLUSION}

We can draw a conclusion that for the treatment of TB-DM patients, we can adopt the same RNTCP guidelines as like TB patients without DM. RNTCP's DOTS holds good irrespective of the glycemic status of the Diabetic patients.

\section{REFERENCES}

1. World Health Organization. Global Tuberculosis Report 2012. WHO/ HTM/TB/2012.6. Geneva, Switzerland: WHO; 2012.

2. Gupta S, Shenoy VP, Bairy I, Srinivasa H, Mukhopadhyay C. Diabetes mellitus and HIV as co-morbidities in tuberculosis patients of rural south India. J Infect Public Health 2011;4:140-4.

3. International Diabetes Federation. In: Unwin N, Whiting D, Guariguata L, et al., editors. IDF Diabetes Atlas. $5^{\text {th }}$ ed. 2012 Update. Brussels, Belgium: International Diabetes Federation; 2012. Available from: http://www.idf. org/diabetesatlas/5e/Update.2012. [Last accessed on 2013 Dec 21].

4. Jeon CY, Murray MB. Diabetes mellitus increases the risk of active tuberculosis: A systematic review of 13 observational studies. PLoS Med 2008;5:e152.

5. Baker MA, Harries AD, Jeon CY, Hart JE, Kapur A, Lönnroth K, et al. The impact of diabetes on tuberculosis treatment outcomes: A systematic review. BMC Med 2011;9:81.

6. Balasubramanian R, Ramanathan $U$, Thyagarajan $K$, Ramachandran R, Rajaram K, Bhaskar D, et al. Evaluation of an intermittent six-month regimen in new pulmonary tuberculosis patients with diabetes mellitus. Indian J Tuberc 2007;54:168-76.

7. TB INDIA 2011, Revised National Tuberculosis Control Programme. Annual Status Report. Ch. 5. Central TB Division, Directorate General of Health Services; p.122.

8. Central TB Division, Directorate General of Health Services, Ministry of Health \& Family Welfare GOI. Revised National Tuberculosis Treatment Control Programme, Technical and Operational Guidelines for Tuberculosis Control. 2005. p. 1-50. Available from: http://www.tbcindia. nic.in/publications. [Last accessed on 2013 Oct 20].

How to cite this article: Ranganath TS, Shivaraj BM. A study on tuberculosis treatment outcome in known diabetic patients treated under Revised National Tuberculosis Control Program in Bengaluru. Int J Med Public Health 2015;5:32-4.

Source of Support: Nil, Conflict of Interest: None declared. 